\title{
Cosmic Expansion: The Dynamic Force Source for All Planetary Tectonic Movements
}

\author{
Jian'an Wang \\ Department of Physics, Shenzhen University, Shenzhen, China \\ Email: wja@szu.edu.cn
}

How to cite this paper: Wang, J.A. (2020) Cosmic Expansion: The Dynamic Force Source for All Planetary Tectonic Movements. Journal of Modern Physics, 11, 407-431. https://doi.org/10.4236/jmp.2020.113026

Received: February 7, 2020

Accepted: March 14, 2020

Published: March 17, 2020

Copyright (c) 2020 by author(s) and Scientific Research Publishing Inc. This work is licensed under the Creative Commons Attribution International License (CC BY 4.0).

http://creativecommons.org/licenses/by/4.0/ (c) (i) Open Access

\begin{abstract}
In this paper, the relationship between the geodynamics and cosmic expansion is analyzed and demonstrated from the basic physical principles and various natural phenomena, and the conclusion is drawn that cosmic expansion is the dynamic force source of all planetary tectonic movements in the universe. The energy for the formation and change of landscape and the energy of earthquakes and volcanic eruptions all come from the cosmic expansion. With the cosmic expansion, the energy density of space is decreasing, the atoms and molecules of all matter in the universe are growing, and the magma is expanding and producing gases. As the earth's internal pressure rises, the mechanical energy that accumulates within the magma forms the driving force of the earth's various tectonic movements, and the release of these energy and matter (expansive magma and high-pressure gases) leads to the formation and the changes of the landform (such as orogenesis, epeirogenesis, the formation of the earth's plates, the Earth expansion, the seafloor spreading, and the continental drift), as well as to earthquakes and volcanic eruptions. In this paper, the causes of all kinds of earthquakes, especially deep focus earthquakes, are given and almost all known seismic phenomena are explained, the basic principle and method of earthquake prediction are given, and the direction is pointed out for the elimination of earthquakes and the utilization of earthquake energy. Based on the same principle of physics, this paper also shows that the Ice-Age is caused by the acceleration of the speed of the motion of the solar system relative to the Milky Way in certain regions of the Milky Way. The greater the speed of the solar system relative to the Milky Way, the greater the drop in Earth surface temperature.
\end{abstract}

\section{Keywords}

Geodynamics, Tectonic Movement, Seafloor Spreading, Continental Drift, Orogenesis, Epeirogenesis, Deep Focus Earthquakes, Earthquake Prediction, Ice Age 


\section{Introduction}

There have been numerous theories of geodynamics in the past 100 years, and at present there are mainly the following hypotheses [1]:

1) Hypothesis on the Earth contraction;

2) Hypothesis on the Earth expansion;

3) Hypothesis of the Earth pulsation;

4) Hypothesis on the Earth rotation;

5) Hypothesis on the surge tectonic;

6) A model of layer-block tectonic thermal-upwelling and the Earth's rotation.

The academician of Chinese Academy of Sciences Ma Zhongjin [1] said a reasonable geodynamic hypothesis must satisfy at least three conditions:

1) It can explain the global tectonic characteristics, spatial distribution laws and tectonic evolution process;

2) The dynamic factor it depends on has sufficient energy and its action mode can reasonably explain the characteristics of the tectonic deformation field;

3) It conforms to the basic principles of physics and the physical and chemical properties of earth interior materials.

In terms of the three conditions mentioned above, no hypothesis has been perfect so far.

In the 1960s, geoscience went through a far-reaching revolution. Plate tectonics led us to realize that the surface of the planet on which we are living was divided into rigid plates that have been moving, and that the earth is a dynamic planet, driven by a deep force that causes earthquakes and volcanoes, uplifts mountains and makes the ocean floor to spread, and gradually changes the shape of the earth's surface, thus shaping the spectacular natural landscape on the surface and bringing rich mineral resources to human civilization. However, the revolution is not over, because the source and nature of the driving force behind the planetary tectonic movement are unclear [2].

To sum up, the current geodynamic models are not perfect mainly because the driving force or the energy source for the planetary tectonic movement has not been found.

The purpose of this study is to provide the driving force or energy source for the planetary tectonic movements and to propose a complete geodynamic model. The model not only conforms to the basic principles of physics but also can reasonably explain the various geological tectonic movements, such as orogenesis, epeirogenesis, the formation of the plates, the expansion of the earth, seafloor spreading and continental drift, volcanic eruption and the causes of various earthquakes, especially the deep focus earthquakes, basic principle and method of earthquake prediction. The model can also point out the direction for the future elimination of earthquake and the exploitation and utilization of earthquake energy.

\section{The Relationship between Geodynamics and Cosmic Expansion}

From the formula (5.31) [3], it can be seen that the orbital radius of the electrons 
around the nucleus of the atoms or ions that make up the object decreases with the increase of the velocity of the object in ether. Thus, as the cosmic expansion decelerates, or as the speed of the objects relative to the cosmic etheric system decreases, all the atoms and ions (ions containing orbital electrons) that make up the objects grow larger. So as the cosmic expansion decelerates, the atoms or ions that make up all the earth's material, including the solid crust, underground magma, water, and air, are expanding.

Because the underground magma is in a high-temperature fluid or liquid state, the magma atoms are mostly in an ionic state. As the magma atoms or ions grow larger, the distance between atoms or ions becomes larger and the attraction between atoms or ions becomes smaller, leading to the volatile matter of the magma to release gases. So the underground magma is bubbling and expanding like a foaming foam that continues to produce gas and expand. Therefore, as the cosmic expansion decelerates, the internal hydraulic and pneumatic pressure of the Earth will continue to rise, and the elastic potential energy accumulated in the Earth's magma provides the driving force for the various tectonic movements of the Earth, and the release of the energy and matter (foaming magma and compressed gases) have led to the formation and change of landforms (such as the orogenesis, the epeirogenesis, the formation of plates, the expansion of the earth, the seafloor spreading and the continental drift), and to earthquakes and volcanic eruptions. So the cosmic expansion is the source of the driving force or the source of the energy for the tectonic movements of the earth and all the planets in the universe.

From the formation of natural diamonds and various crystalline minerals in the earth's crust, and from the evidence that meteorites generally have a mineral density greater than earth's, we can learn that all atoms are growing larger as the universe expands. From the fact that there are gases from the volcanic eruption and the fact that the more recent the eruption is the less dense the volcanic rock is, we can learn that the underground magma is continuously producing gases and expanding. From the formation, maintenance and change of earth atmosphere, we can learn that underground magma is continuously producing gases. From a great deal of factual evidence from the geometry, geology, astronomy and geophysics of continental forms, we can learn that the earth has been expanding. This geodynamics model gives reasonable explanations of various tectonic movements, such as orogeny, epeirogenic movement, seafloor spreading, continental drift, volcanic eruptions, and reasonable explanations of the causes of various earthquakes (including deep-focus earthquake) and various seismic phenomena.

\subsection{From the Formation of Natural Diamonds and Various Crystalline Minerals in the Earth's Crust, and from the Evidence That Meteorites Generally Have a Mineral Density Greater than Earth's, We Can Learn That All Atoms Are Growing Larger as the Universe Expands}

Why can't the lava from the volcano now form crystalline minerals such as diamond, gem, granite and so on after solidification, but light volcanic rocks? Ac- 
cording to formula (5.31) [3], all atoms will increase with the decelerating expansion of the universe, so the atoms and molecules of magma are much larger than those of hundreds of millions or billions of years ago, and under the normal pressure of one atmosphere, minerals such as diamond, gem and granite cannot be formed by natural solidification. Crustal minerals such as diamonds, gemstones and granites were formed by magma cooling and solidifying at different ages during the earth's crustal formation process. Diamonds were formed billions of years ago by natural cooling and solidification of magma on the earth's surface or at shallow crust at about one atmospheric pressure. This is why we can find or mine diamonds on the surface of the earth or in the shallow layers of the earth's crust. Natural diamonds must be found in ancient continental plates such as Africa and Siberia, not in young craters or on young continental or oceanic crusts.

In addition, meteorites have a high probability of containing diamonds because of their small size and quick solidification (the time of solidification is very early).

So the fact that natural diamonds and various crystalline minerals formed on the earth's surface, and that meteorites have a higher mineral density than earth, provides evidence that atoms keep getting bigger as the universe expands.

\subsection{From the Fact That There Are Gases from the Volcanic Eruption and the Fact That the More Recent the Eruption Is the Less Dense the Volcanic Rock Is, We Can Learn That the Underground Magma Is Continuously Producing Gases and Expanding}

The fact that underground magma continues to produce gases from volcanic eruptions can be verified by the fact that carbon dioxide, hydrogen sulfide, sulfur dioxide, hydrogen chloride, hydrogen fluoride, nitrogen, argon, methane, carbon monoxide and other gases are accompanied by the eruptions.

We can measure the specific gravity of volcanic rock in the vicinity of the crater at different ages, indicating that the closer the eruption is, the less dense the rock is. As shown in Figure 1, the density of 6-edged basalt volcanic rocks in the ancient crater of the Changle Northern Rock in Shandong province of China 18 million years ago is significantly larger than that of the Shishan volcanic group in Haikou city, Hainan province of China about 13,000 years ago, as shown in Figure 2.

As the universe expands, the atoms and ions of the underground magma keep getting bigger, the magma keeps producing gases at an accelerating rate, so the magma has more and more bubbles and the bubbles are getting bigger and bigger, and the magma keeps expanding. That's why the closer the age of the eruption, the less dense the rock.

\subsection{From the Formation, Maintenance and Change of Earth Atmosphere, We Can Learn That Underground Magma Has Been Producing Gases Continuously}

As the universe expands, the atoms and molecules of everything in the universe 


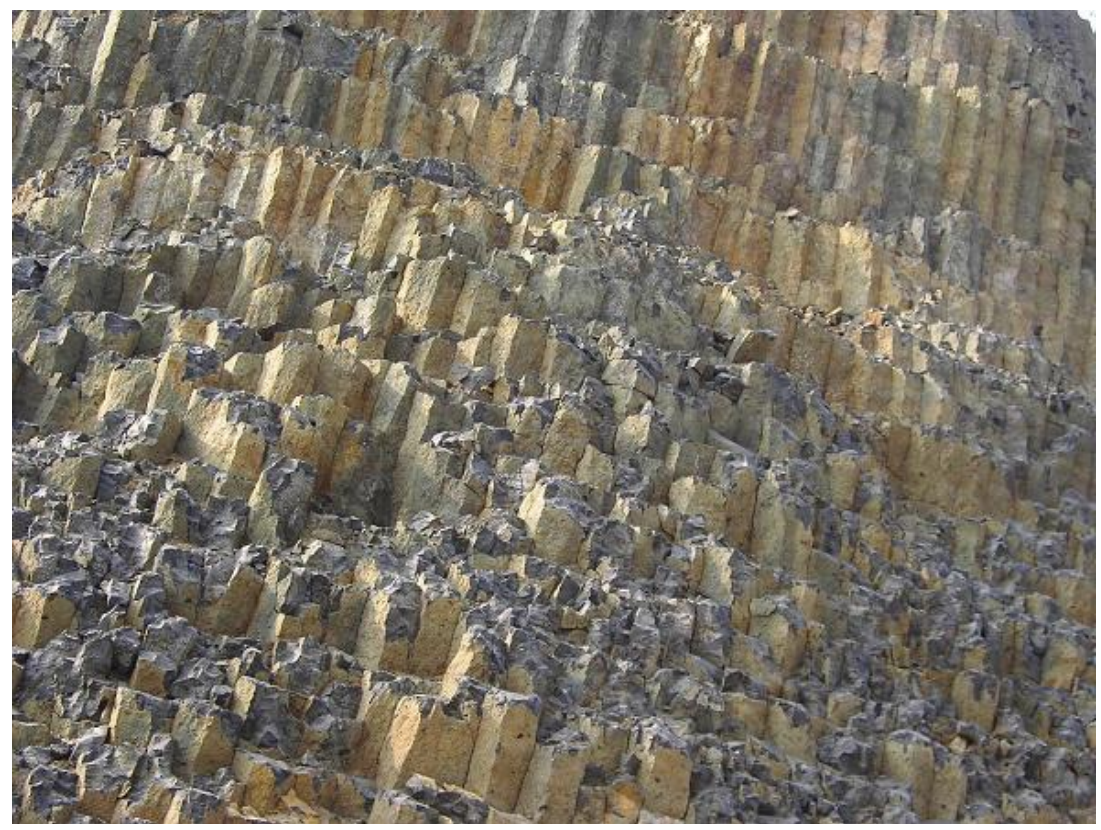

Figure 1. 6-angled basalt volcanic rocks from the ancient crater 18 million years ago in Changle North Rock, Shandong Province.

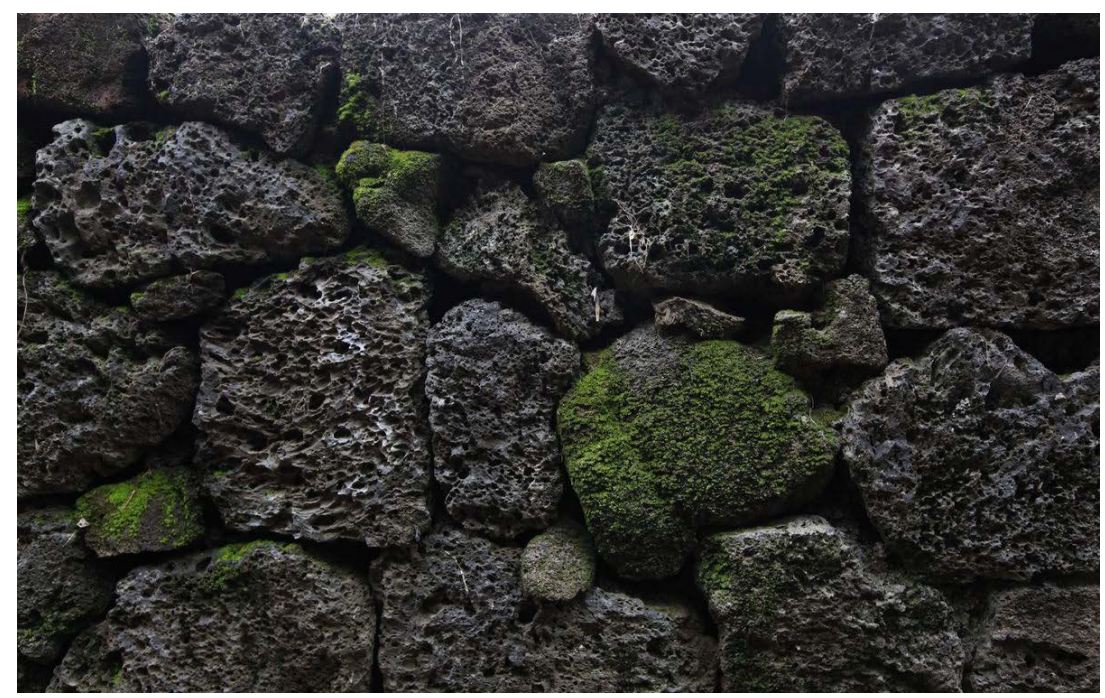

Figure 2. Volcanic rocks from Shishan volcanic group about 13,000 years ago, in Haikou, Hainan province.

keep getting bigger. In the early days of the earth, small molecules of some volatile materials in the magma, such as hydrogen and helium, broke free from the magma and became free molecules. These free molecules gathered on the surface of the planet after leaving the magma to form the planet's primeval atmosphere by the gravity. Since atmospheric molecules obey Maxwell's law of speed distribution, there is always a certain percentage of gas molecules at every moment that exceed the second cosmic velocity, so the atmosphere is constantly losing molecules to space. The earth's atmosphere would not have lasted for billions of years without the constant replenishment of gases. It is because the gases re- 
leased by the underground magma continue to replenish the air lost in the atmosphere that the Earth's atmosphere has been able to remain so long. As the cosmic expansion continues to slow down, the magma atoms continue to grow, the weight and size of the molecule released from the magma keep increasing and the composition of the atmosphere is constantly changing. In the early days of the Earth, underground magma mainly released small molecule gases such as hydrogen and helium, and now it mainly releases large molecule gases such as nitrogen, carbon dioxide, sulfur dioxide and hydrogen sulfide. A paper by the university of California, published in Science on April 6, 2018 [4] claimed to have found that up to $26 \%$ of nitrogen in the ecosystem came from the earth's lithosphere bedrock (this paper suggests from underground magma).

The disappearance of the atmosphere of the moon and mars is due to the fact that the mass of the moon and Mars is much smaller than that of the Earth (the masses of the moon and Mars are about 1/81 and 1/10 of that of Earth, respectively), and that the underground magma has completely solidified and stopped producing gas.

\subsection{The Evidence of Earth's Expansion}

In the article "the theory of earth expansion, its development and its main facts" [5], a large number of facts were provided for the continuous expansion of the earth from the geometry of the continental form, geology, astronomy, geophysics and other aspects.

\subsection{Explanations of the Formation and Variation of the Earth landforms by the Geodynamics Model Based on Cosmic Expansion}

The formation of earth landforms such as the land, the sea, the mountain chain, the cave, the mountain and the basin are caused by cosmic expansion. The formation of the earth's plates, the seafloor spreading, and the continental drift are also caused by cosmic expansion.

As the Earth's surface continues to cool, the Earth's surface slowly formed a solid monolithic shell, the lithosphere. The outer layer of the lithosphere is solid, and the further inside, the higher the temperature, the softer. The continuous gas production of underground magma causes the expansion rate of underground magma to be greater than that of solid lithosphere. Before the formation of the Earth's plates, or before the broke up of the Earth's lithosphere, the Earth was like a closed, thin-walled container filled with hot water at $100^{\circ} \mathrm{C}$ and continuously heated. With the expansion of underground magma and the accumulation of high-pressure gases under the lithosphere, these foaming magma and high-pressure gases constantly changed the shape of the lithosphere both leading to violent orogenic and epeirogenetic movements.

With the cosmic expansion the gases produced within the Earth grew, and these gases gathered beneath the lithosphere formed a gas layer. Because of the inhomogeneity of the lithospheric material structure, the rate at which each part 
cools and solidifies will vary, and those relatively weak local areas will be uplifted by the gas pressure to form mountains, while those with no or relatively few uplifts will form valleys, basins, or plains. The gases that partially jacked up the lithosphere to form the mountains would eventually escape the earth and leave an exhaust passage (the original cave) underground. Thus, one end of the cave must be connected to the atmosphere and the other to the mantle.

With the continuous cooling of the earth's surface, the lithosphere has been constantly thickening. When the lithosphere reached a certain thickness, the pressure required to rupture the lithosphere is less than that required for the partial uplift of the lithosphere, the foaming magma and high-pressure gas finally ruptured the lithosphere into several large plates.

Because the sudden rupture of the lithosphere caused the sudden expansion of the earth and the sudden separation of the primitive plates formed after the rupture of the lithosphere, the surface area of the earth suddenly increased a lot. Because the curvature of the primitive plates formed after the rupture of the lithosphere is smaller than that of the expanded earth's surface, a layer of gas accumulated under the primitive plates after the rupture of the lithosphere. Because there is a gas layer under the primitive plates, the primitive plates have been floating on the magma and form the continents.

Because these new crusts, formed by magma cooling from the gap between the primitive plates, are relatively low in topography, they constitute the ocean floors. Because these newly formed crusts (ocean floors) are formed by magma cooling exposed by the gap between the primitive plates formed by lithosphere rupture, there is a great difference in geological age between continental crusts and oceanic crusts.

Because there are fragments in the middle of the gap between the primitive plates during the rupture of the lithosphere, these fragments have been remaining in their original position during the seafloor spreading, thus becoming island or continental fragments.

Because the sudden rupture of the lithosphere lead to a massive release of underground gas, including water vapor, air and water vapor in the atmosphere suddenly increased. The cooling of the water vapor formed the original ocean.

Because the oceanic crusts are thin, the tectonic movement in the vertical direction of the earth after the rupture of the lithosphere has been being concentrated on the oceanic crusts mainly.

As the universe continues to expand, the underground magma continues to produce gases and causes the earth to continue to expand, causing the newly formed ocean crusts to continue to burst, and the magma continues to gush out at the fractures of the ocean crusts to form and renew mid-oceanic ridges in the ocean. As the underground magma continues to expand, the ocean floor expands on both sides of the mid-oceanic ridge, and underground magma gushes out to form new ocean floor. This is how the ocean floors spread and continents drift. Thus, the closer to the mid-oceanic ridges, the younger the ocean floor.

It is the expanding force of the underground magma, not the convection of 
the earth's mantle, that cause the seafloor to spread, the mantle plumes and plate subductions do not exist. Because the earth is expanding, plates are moving away from each other, so plate squeezes and collisions do not exist. This shows that the earthquake is not caused by plate squeeze or collision.

Because the gaps between plates are cemented with solidified magma, the plates tear away from each other as the earth expands, starting at a point in the gap. So the path of the continental drift is an arc.

In the early days of the ocean floor spreading, the ocean crust (the gap between the primitive plates) was narrow and thin, although the water above the ocean crust has weight, but water has no stress to resist deformations, so as the magma pressure inside the Earth increased, some ocean ridges and the surrounding ocean crust would be uplifted by underground magma to form new land and mountains above the sea level. This is why fossils of ancient marine animals and plants have been found in some mountains, such as the Himalayas.

Because under the force of underground magma expansion the earth continues to expand and the plate curvature becomes smaller and smaller, the gap between the two plates will continue to bulge outward along the radius of the earth, causing these mountain ranges formed along the gap between two plates, such as the Himalayas, to rise.

As the earth expands with the seafloor spreading, the curvature of the earth's surface becomes smaller and smaller. Therefore, the older the plate, the greater the curvature. Since the continental crust is older than the oceanic crust, the boundary between the continental crust and the oceanic crust forms the trench.

The continuous gas production of underground magma makes the expansion rate of underground magma larger than that of the water on earth, so the ratio of the volume of water, including ice, to the volume of the earth has been decreasing and the ratio of land area to ocean area has been increasing.

\subsection{Explanation of Volcanic Eruptions by the Cosmic Expansion Geodynamic Model}

As the universe continues to expand, the magma atoms inside the Earth continue to grow and the magma continue to produce gases. Bubbles gathered by these gases are constantly floating upward under the buoyancy of the magma and converge in the plate fault zones and craters. In an active volcano, magma containing bubbles is constantly spewing out of the crater. In an extinct volcano, when the pressure of the bubbling magma is greater than the threshold, the magma breaks through the crater blockage and erupts.

\subsection{Explanations of the Causes of Various Earthquakes by the Cosmic Expansion Geodynamic Model}

According to this geodynamic model, earthquakes are caused by cosmic expansion that causes the underground magma to continuously separate out gases.

As the universe continues to expand, the magma atoms continue to grow, leading to the continued generation of gases in the magma (primitive air, now 
mainly nitrogen and carbon dioxide). Since these gases are produced in the mantle and core, and at high temperatures in the mantle and core gas molecules are ionized. These bubbles, driven upward by the buoyancy of the magma, accumulate beneath the plates and in cracks in the fracture zones. These high temperature and high pressure charged gases, which gather under the lithosphere, are constantly looking for a breakthrough to release. Because the solidification layer at the junction between two plates is relatively weak, it is easy to be broken, resulting in the sudden release of this high temperature and high pressure charged gases (explosion)-earthquake.

On June 12, 2008, after Chinese Wenchuan earthquake, "People's Weekly", titled "Wang Shencun: A lonely fan of scientific research of the field of earthquakes", reported on his thirty-two years of silent research and exploration of the mysteries of earthquakes, and published the full text of chapter $1-4$ of his book "reveal the secret of nature-secrets of earthquakes". "Reveal the secret of nature-secrets of earthquakes", also known as "new theory of earthquakes" or "earthquake gas explosion theory", was proposed by author Wang Shencun shortly after the 7.8-magnitude Chinese Tangshan earthquake on July 28, 1976, according to the phenomenon of gas explosion occurring during the earthquake: light (flash), sound (explosion), gas (gas breaking through the ground and rising into the air), and quake (earthquake), and after many years of difficult research and exploration and simulation tests, a more systematic theory of seismic gas explosion was preliminarily completed in October 1981, which opened up a new way to solve the world problem of earthquake [6].

The cause of earthquakes derived from this Cosmic Expansion Geodynamic Model is in perfect agreement with Mr. Wang Shencun's Earthquake Gas Explosion Theory. Since this Cosmic Expansion Geodynamic Model is derived from the conclusion of the Modified Special Relativity [3], and Mr. Wang Shencun's Earthquake Gas Explosion Theory is summed up by a large number of seismic phenomena, the credibility of the conclusion that earthquake is caused by the explosion of high temperature and high pressure charged gas is very high.

\subsubsection{The Mechanism of Natural Earthquakes}

As the universe expands and the underground magma continues to produce gases, the pressure on the high-temperature and high-pressure charged gases that accumulate beneath the lithosphere increases. When the pressure is greater than the strength of the surrounding rock mass, a gas explosion occurs. This is how natural earthquakes occur.

\subsubsection{The Mechanism of Artificial Earthquakes}

The explosion of the high temperature and high pressure charged gases stored under the lithosphere can also be triggered by man-made factors, such as storage or release of water from reservoirs, underground nuclear experiments or large equivalent TNT underground explosions, which is the mechanism of artificial earthquakes. 


\subsubsection{The Mechanism of Deep-Focus Earthquake}

The deep-focus earthquake is the earthquake with a depth of more than $300 \mathrm{~km}$, the deepest known deep-focus earthquake with a depth of $720 \mathrm{~km}$. Studies have shown that rocks below tens of kilometers are in soft plastic state. Below $720 \mathrm{~km}$ the temperatures is above $1100^{\circ} \mathrm{C}$ degrees and the rock is basically fluid. As the universe expands, magma atoms expand and separate gas molecules (actually ions) that gather into bubbles. These bubbles move upwards under the buoyancy of the magma. Because the farther away from the center of the earth, the lower the hydraulic pressure of the magma, the lower the temperature, the thicker the magma. Therefore, in the process of the bubble floating upward, the resistance encountered is increasing, and the surface tension of the bubble is also increasing, and the hydraulic pressure outside the bubble is decreasing. Bubbles get bigger and bigger as they rise upward (more and more bubbles merge). Because the earth's radius is very large and the velocity of the bubble floating up is very small (because the magma is very dense), the process of the bubble floating up is very long. In the long process of bubble floating, the elastic potential energy gathering in the bubbles will be larger and larger, and when the pressure inside the bubble is greater than the sum of the hydraulic pressure of the external magma and the surface tension of the bubble, the bubble will explode. It can be seen that the deep-focus earthquake is the explosion of high pressure bubbles in the underground magma.

\subsection{Explanations of Seismic Phenomena by the Cosmic Expansion Geodynamic Model}

In the long-term practice, the ancient Chinese people realized that earthquakes have precursors, and left a wealth of records about earthquake precursors. Liang Guanghe's article "new knowledge of earthquakes" [7] and Yue Zhongqi's blog "the causes that each airs his own views for strong seismicity and the prediction" [8] list a large number of natural phenomena that have been observed before, during and after earthquakes based on seismic investigations and research. The author summarized the above seismic phenomena and explained them one by one by using this cosmic expansion geodynamic model:

\subsubsection{Explanations of the Main Natural Anomalies before Earthquakes, the Accompanying Phenomena during Earthquakes and the Phenomena after Earthquakes}

Because there will be a lot of high temperature and high pressure charged gas gathering and activity in the underground of the earthquake area before the earthquake occurs, there will be many abnormal natural phenomena. The accumulation and slow release of high temperature and high pressure charged gases will not only affect the nearby electromagnetic field but also change the temperature and weather. In addition, the accumulation and release of these high temperature and high pressure charged gases will also lead to local underground pressure changes, resulting in the formation deformation and abnormal sound. The variation of the underground pressure and the deformation of the formation 
will lead to the change of the groundwater level.

1) Groundwater anomalies: Groundwater includes well water, spring water, etc. The main anomalies are muddy, bubbling, churning, temperature rise, discoloration, flavor change, sudden rise, sudden drop, well hole deformation, spring source suddenly dried up or gushing, etc.

Explanation: The anomaly of groundwater is caused by the accumulation and release of underground high temperature and high pressure charged gases in the preseismic area. The slow release of high temperature and high pressure charged gases accumulated underground can cause particles of underground minerals or soil dust to enter the water and cause well or spring water to become muddy, bubbling, churning, warming, discoloring, or flavoring. Because the change of the high temperature and high pressure charged gas pressure in the underground will change the hydraulic pressure of the groundwater and cause the deformation and movement of the formation, it will lead to the sudden rise or sudden drop of the well water, the deformation of the well hole, sudden depletion or emission of the spring source, etc.

2) Biological anomalies: Before the earthquake, in addition to animals have abnormal behavior, some plants also have abnormal response, such as inappropriate season of germination, flowering, fruiting or a large area of wither and unusually exuberant.

Explanation: The abnormality of animals is mainly due to the underground high temperature and high pressure charged gas release in the pre-earthquake zone, which leads to the interference of the geomagnetic field, the abnormal sound and the peculiar smell. The plant anomaly is mainly due to the slow release of high temperature and high pressure charged gases in the in the pre-earthquake zone. Because the temperature of the gases is very high, the release of these gases can change the temperature of the soil and air in the zone, resulting in the germination, flowering and fruiting of plants during the inappropriate season. Because the main components of seismic gases are nitrogen and carbon dioxide, and these elements are the nutrients that plants need, the slow release of these gases can cause plants to become unusually lush. But if the released gas is too thick, it will cause the plant to wither in large area.

3) Weather anomalies: Before earthquakes, the weather is often abnormal. The main abnormal phenomena of the weather are: sultry, long drought or steady rain, yellow fog everywhere, dark daylight, strange wind raging, hail in June and so on.

Explanation: The gathering and slow release of underground high temperature and high pressure charged gases in the earthquake zone before the earthquake will certainly have an impact on the weather in the earthquake zone. The sultry weather is mainly caused by the release of the underground hot gases and the evaporation of the groundwater caused by the release of the underground hot gases. If there isn't much ground water in the zone, then the released hot gases will lead to a prolonged drought, and if the zone is rich in groundwater, the released hot gases will lead to the evaporation of groundwater, resulting in 
steady rain. Since the charged gases can absorb dust particles during the underground flow, the release of these charged gases into the upper air may cause the high-altitude water vapor to form the hailstorm, so there may be hailstorms in June. The release of these charged gases containing dust particles from the ground can also lead to yellow fog and dark sunlight. The strange wind raging phenomenon should be caused by the rising hot air from the release of the high temperature and high pressure charged gases stored underground.

4) The emergence of the Earthquake Cloud: Earthquake Cloud is a kind of cloud in non-meteorological classification that indicates earthquakes. At present, the academic community is skeptical about the Earthquake Clouds, believing Earthquake Clouds to be pseudoscience, because, according to the existing seismic theory, earthquakes are caused by the accumulation and release of crustal plate stress due to crustal movement, and the slow movement of the crusts is not related to the meteorological phenomenon for a short time. There are only folk enthusiasts to explore the earthquake cloud in China, Japan, Indonesia and other countries.

Explanation: Because a large amount of high-temperature and high-pressure charged gases will accumulate underground in the earthquake area before the earthquake occurs, when these high-temperature and high-pressure charged gases accumulate to a certain amount, they will overflow from the ground (because when the pressure exceeds a certain value the surrounding rock mass that gathers these high-pressure gases will leak). Because the charged gases can absorb dust particles during underground flow, the release of a large amount high-temperature charged gases from the ground above the surrounding rock mass (possibly source) where these gases are gathered into the atmosphere can lead to the generation of this particular cloud-earthquake cloud. As a result, many earthquake clouds are strip-shaped and point to the epicenter at one end. If these gases are released from multiple outlets (potential earthquake sources) in the fault zone, an earthquake cloud as shown in Figure 3 will result. The emergence of the earthquake cloud is similar to the situation that the river level has exceeded the warning line and began to overflow (the possibility of a dam broke is very high). Therefore, the emergence of the earthquake clouds indicates that the probability of a large earthquake is very high.

5) Underground sound anomaly: The underground sound anomaly refers to the sound from underground before earthquakes that is like the thunder of cannon, or the sound of heavy vehicle driving, or the sound of the strong wind surge and so on.

Explanation: Earthquakes are caused by the explosions of high temperature and high pressure charged gases in the ground. Because underground sound travels faster than the shock wave from gas explosions, the sound of cannon thunder will be heard before the earthquake. A large amount of gases released by a gas explosion flowing underground, especially in underground caves, can produce the sound of heavy vehicle driving, or the sound of the strong wind surge. 


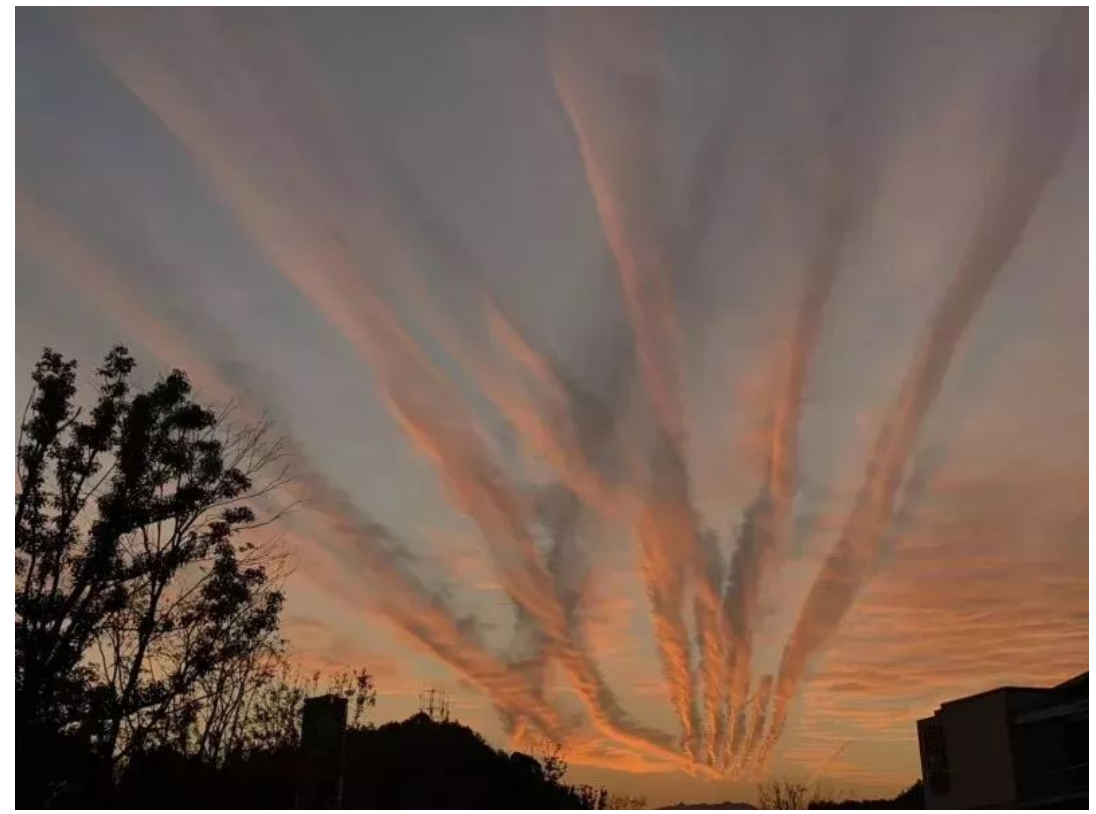

Figure 3. Earthquake clouds.

6) Abnormal ground light: Abnormal ground light refers to the light from the ground before an earthquake, its color is varied, rare mixed colors in daily life can be seen, such as silver blue, white purple, but mainly red and white; its shape is also varied, there are ribbon, ball, columnar, diffuse, etc. Generally, ground light appears in a wide range, mostly in the first few hours to a few minutes before the earthquake, lasting several seconds.

Explanation: A large amount of high temperature and high pressure charged gases will be gathered underground in the earthquake area before the earthquake occurs. The ground-light phenomenon should be the discharge on the ground of these charged gases when they flow from the ground to the air before the earthquake.

7) Abnormal ground gas: Abnormal ground gas refers to the fog from the ground before the earthquake. This fog, with a variety of colors, such as white, black, yellow, and sometimes colorless, often occurs within a few days to a few minutes before the earthquake, often accompanied by a strange smell, sometimes accompanied by sound or high temperature.

Explanation: The ground gas phenomenon is caused by the release of high-temperature and high-pressure charged gases gathered underground before the earthquake. Because the charged gas can absorb the dust particles of various substances it passing through during the underground flow, the odour should be caused by the dust particles of certain substances. Since the gases released are very hot, of course there will be high temperature phenomenon accompanied by. The rapid flow of a large amount of gas underground certainly will make some sounds.

8) Abnormal ground movement: Abnormal ground movement refers to the shaking of the ground before the earthquake. Before the earthquake, people 
sometimes feel the ground shaking, which is different from the earthquake. The shake is so slow that seismometers often miss it, but many people can feel it.

Explanation: Abnormal ground movement is a small shaking caused by the high pressure gas accumulated underground in the seismic area before the earthquake, which pushes up the local strata and causes the strata to be unstable.

9) Abnormal ground bulge: Abnormal ground bulge refers to bulges formed on the ground before the earthquake

Explanation: The abnormal ground bulge is caused by the high pressure gases accumulated underground in the earthquake area before the earthquake.

10) Electromagnetic phenomena associated with earthquakes: To sum up, the electromagnetic phenomena associated with earthquakes are the production of strong current and the sudden change of electromagnetic field near the quake zone. The electrical current generated by an earthquake is very strong. A magnitude 6 earthquake can generate a current of up to 100,000 amperes and a magnitude 7 earthquake can generate a current of up to 1 million amperes [7]. The maximum current on a typical household meter is usually no more than 60 amperes. How does such a strong current come about?

Explanation: Because the earthquake is formed by the explosion of high temperature and high pressure charged gases gathered underground, there will be a rapid underground flow of a large number of ionic gas molecules when the earthquake occurs, thus forming a strong current and producing a strong magnetic field. The strong magnetic field generated by an earthquake can cause a sudden change in the electromagnetic field near the earthquake area.

11) Large earthquakes are often the metallogenic process of underground metalliferous minerals. Scientific research showed that earthquakes can precipitate gold deposits.

Explanation: Because seismic gases are produced in the mantle and core, the temperature of these gases is very high. Large amounts of hot seismic gases flowing through the earth's crust during a great earthquake can cause passing gold particles to melt and solidify into gold nuggets, or cause metalliferous minerals to melt and produce reduction reactions to form metals.

12) During an earthquake, people first hear the sound and then feel the quake.

Explanation: The earthquake is caused by the explosion of high-temperature and high-pressure gases formed by the accumulation of charged gas molecules separated by underground magma. Because the sound wave travels faster in the rock than the shock wave produced by the explosion of high-pressure gas, people first hear the sound and then feel the quake.

13) A great earthquake may immediately darken the sky

Explanation: The earthquake was caused by the sudden release (explosion) of high-temperature and high-pressure gases formed by the accumulation of charged gas molecules separated by underground magma. The charged gas traps dust particles as it travels underground. A great earthquake can immediately darken the sky because of the sudden release of a large amount of gas adsorbed 
with dust particles from the ground into the atmosphere.

14) The air temperature may begin to drop immediately during or after an earthquake

Explanation: Because the earthquake is caused by the sudden release (explosion) of high pressure gas underground, and the sudden decompression release of high pressure gas will absorb the heat of the surrounding material, the temperature in the earthquake area will suddenly drop during the earthquake.

15) Heavy rain or snow may fall in hours after a strong earthquake

Explanation: Because the earthquake is caused by the sudden release (explosion) of high pressure gas underground, and the sudden decompression release of high pressure gas will absorb the heat of the surrounding material, the temperature in the earthquake area will suddenly drop during the earthquake. A sudden drop in temperature can cause water vapor in the air to quickly condense into water droplets, or snowflakes. So it may rain or snow in a few hours after a great earthquake.

16) There is underground wind in an earthquake

Explanation: Because the earthquake is caused by the sudden release (explosion) of high pressure gas underground, the flow of the gas from the earthquake forms the underground wind.

17) Before and after an earthquake, there may be natural gas ejection, explosion, and combustion

Explanation: Because the earthquake is caused by the sudden release (explosion) of high-temperature and high-pressure gases formed by the accumulation of charged gas molecules separated by underground magma, if the source is below the natural gas field, the earthquake can cause a large amount of gas to be released into the natural gas field, so the gas reserves and pressure in the natural gas field will increase. Because a large amount of charged gas enters into the natural gas field when an earthquake occurs, if this gas mixture in the natural gas field is ejected into the atmosphere, it could lead to spontaneous combustion or explosion.

18) During an earthquake, a fire, even a huge fire, may break out in a city

Explanation: Because earthquakes are caused by the sudden release (explosion) of high-temperature and high-pressure charged gases formed by the accumulation of charged gas molecules separated by underground magma, the encounter of these high-temperature charged gases in the atmosphere with leaking liquefied petroleum gas, gasoline or other flammable gases or liquids can lead to the combustion or explosion of these flammable gases and liquids. Therefore, there may be a fire or even a huge fire in the city during the earthquake.

19) Earthquakes can trigger forest fires (the author speculates)

Explanation: There are frequent forest fires on Earth [9], such as the Amazon forest fire in August 2019, the forest fire in California in September 2019, and the forest fire in Victoria, Australia, in November 2019. How did these forest 
fires come about? Noting that California and Amazonian forests are located in the Pacific seismic belt, Australia's Victoria is also the region where the earthquake occurred. Because earthquakes are caused by the sudden release (explosion) of high-temperature and high-pressure charged gases formed by the accumulation of charged gas molecules separated by underground magma, if the earthquake occurs in the forest area, especially in the forest area where there is no rain for a long time, the instantaneous release of a large amount of high temperature charged gas is completely likely to ignite the hay, fallen leaves and dead trees of the forest from many large areas, thus leading to the occurrence of forest fire. It can be seen that the forest fire caused by the earthquake has the characteristics of igniting in a large area and many places at the same time, and starting very quickly, it has no time to extinguish.

20) In strong earthquakes, local mountain soil and rock are thrown out by gas, mountain collapse and earth crack, and the coseismic surface soil is broken (tensile and shear type)

Explanation: Because earthquakes are caused by the explosion of high temperature and high-pressure charged gas, in strong earthquakes, local mountain soil and rock will be thrown out by the gas, mountain collapse and earth crack. Because the shock wave produced by the underground gas explosion is spherical longitudinal wave with the explosion point as the center, the rupture of the coseismic surface soil is tensional and shear type.

21) There may be a huge increase in the underground natural gas reserve after the earthquake

Explanation: If the earthquake source is below the natural gas field, because the earthquake may cause a large amount of gas to be released into the natural gas field, the gas reserve in the natural gas field may has a huge increase, but the total content of natural gas will not increase, and the nitrogen and carbon dioxide content in the natural gas will increase a lot.

22) Earth's rotation rate may accelerate after a great earthquake

Explanation: Since a large quantity of high-pressure gas that accumulates beneath the earth's crusts are released into the atmosphere during a great earthquake, the crust sinks slightly and the earth's moment of inertia becomes smaller. Because of the conservation of angular momentum on the earth's rotation, the angular speed of the earth's rotation will accelerate slightly.

23) After a great earthquake, the ground has a large and wide range of horizontal displacement and settlement

Explanation: Because earthquakes are caused by the sudden release (explosion) of high-temperature and high-pressure gases formed by the accumulation of charged gas molecules separated by underground magma. Before the earthquake, the local crust of the earthquake area is lifted up by the high pressure gas, and after the earthquake the high pressure gas is released from the underground into the atmosphere, so after a great earthquake, the ground in the earthquake area will settle down greatly and widely. Due to the geological structure of the 
ground in the process of subsidence will also produce horizontal movement.

\subsubsection{Explanations to the Laws of Earthquake Occurrence}

1) The sites of the earthquake are located in the weak zones and deep fault zones of the crustal geological material

Explanation: Earthquakes are caused by the sudden release (explosion) of high temperature and high pressure gases formed by the accumulation of charged gas molecules separated by underground magma. Because the weak zone of geological materials can be easily destroyed by the high pressure gas, the sites of the earthquake are located in the weak zones of crustal geological material. Because the deep fault zones tend to gather bubbles of gas separated by underground magma (the bubbles float upward by the magmatic buoyancy, they can easily enter the cracks in the deep fault zone during the process of floating), and the fault zones are prone to rupture, the sites of the earthquake are located in the deep fault zones.

2) Where many weak or small earthquakes occur, no strong or great earthquake will occur

Explanation: Because in the place where many weak earthquakes and small earthquakes occur, the accumulated underground high pressure gas is released in time, and the energy gathered by the underground high pressure gas will not be large, so there will be no strong or great earthquake.

3) The focal depth of medium and small earthquakes varies greatly, while the focal depth of strong and great earthquakes is usually shallow (within $25 \mathrm{~km}$ depth)

Explanation: Because the deeper the underground, the higher the temperature, the softer the crust, the smaller the energy accumulated before the explosion of high-pressure gas; in addition, the deeper the underground pressure (mainly the pressure formed by the formation weight), the smaller the pressure difference between the bubbles formed by high-pressure gas and the outer space; therefore, the deeper the underground, the more difficult it is to form a strong or great earthquake. Within $25 \mathrm{~km}$ of depth, the underground temperature is not high, and the strength of underground rock is generally relatively large. In addition, the underground pressure within $25 \mathrm{~km}$ is relatively small. Therefore, if the surrounding rock mass with the accumulation of underground gas is relatively strong, the pressure difference of the high pressure gas gathered in the rock bed before explosion can be very large relative to the outer space, and the elastic potential energy accumulated can be very high. Therefore, the source depth of strong earthquakes and great earthquakes is usually shallow (within $25 \mathrm{~km}$ depth). If the surrounding rock mass for the accumulated underground gas is not strong enough, then within $25 \mathrm{~km}$ depth can also produce small and medium earthquakes.

4) The sequence of earthquake types is diverse, such as foreshock main shock aftershock type, main shock aftershock type, double main shock type, etc

Explanation: Earthquakes are caused by the sudden release (explosion) of high 
temperature and high pressure gas formed by the accumulation of charged gas molecules separated by underground magma. Foreshocks, main shocks and aftershocks are all formed by the explosion of this high-pressure gas. Due to the diversity of geological structures in the geological fault zone, that is to say, the surrounding rock masses containing such high temperature and high pressure charged gas are different in size and structure, so the sequence of series explosions generated by the high-pressure gas gathered in the surrounding rock masses is of course diverse.

5) Earthquakes can be repeated in one place, and the repeated periods vary widely among geological regions, for decades, hundreds or thousands of years

Explanation: Because earthquakes occur in fault zones where underground gas is easily accumulated and the fault zone does not disappear as a result of earthquakes, earthquakes can be repeated in one place. After the earthquake, because of the formation of many underground gas channels in the earthquake area, it is temporarily difficult to gather gas below the earthquake area. Over time, the underground magma solidifies in these gas channels, blocking them, and then allows the underground gas to accumulate below the earthquake area. Due to the different time cycles for the blockage of underground gas channels in different seismic areas and the different time cycles of gas reaccumulation, the seismic repetition cycles in different geological areas vary greatly, which can be tens, hundreds or thousands of years.

6) The earthquake area may have seismicity gaps

Explanation: If there is a solid rock bed with a large mass or a solid rock bed connected to the plate as a whole above or obliquely above the earthquake source, the area above the rock bed may form a seismicity gap. Because earthquakes are caused by the explosion of underground high-pressure gas, the bulk of a solid rock bed with a large mass or a solid rock bed connected to a plate as a whole is largely unaffected by shock waves from gas explosions.

7) Earthquakes can cause tsunamis

Explanation: Earthquakes are caused by the explosion of underground high-pressure gas. Because the shock waves from underground gas explosions can be transmitted from the stratum to the ocean, they can cause tsunamis.

8) Coseismic surface fractures observed on sites generally occur in weak strata such as surface soil, weathered soil and coal seams, while coseismic fractures of hard surface rock mass are rarely seen

Explanation: Because the fault of the co-seismic surface is caused by the shock wave generated by the underground gas explosion, and the strength of the shock wave reaching the surface is not enough to break the hard rock mass, but can break the weak strata such as the surface soil, weathered soil and coal seam.

9) The duration of a single earthquake is very short, from seconds to tens of seconds

Explanation: A earthquake is usually caused by a series of explosions of many high-pressure gas pockets that form in a geologic fault zone. Because a single 
earthquake is caused by the explosion of a single high-pressure gas pocket, the duration is very short, from seconds to tens of seconds.

10) The attenuation rate of earthquake intensity along horizontal distance is much lower than that along depth

Explanation: Because the earthquake is caused by the explosion of underground high-pressure gas, on the surface of the ground the seismic wave is circle propagation centered on the epicenter, while in the earth it is spherical propagation centered on the seismic source. Since the circumference of the circle is proportional to the radius of the circle and the surface area of the sphere is proportional to the square of the radius of the sphere, the attenuation rate of the seismic intensity along the horizontal distance is much smaller than that along the depth.

11) The macro-epicentre of an earthquake is located in a weak zone of geological materials (such as in or near a basin)

Explanation: Because the earthquake is caused by the explosion of underground high pressure gas, and the weak zone of geological materials has little ability to withstand shock waves, it is easy to be destroyed by shock waves, so the macro epicenter of an earthquake is located in the weak zone of geological material.

12) The vertical acceleration of the epicentre is greater, and the horizontal acceleration at a distance from the epicentre is greater

Explanation: Because the seismic wave is the longitudinal wave propagating along the radius of a sphere with the gas explosion point as the center of the sphere, the epicentre has a greater vertical acceleration and at a distance from the epicentre has a greater horizontal acceleration.

13) The period of calm in each fault zone prior to a strong earthquake is decades, hundreds, or thousands of years

Explanation: Because fractures in the fault zone are vertical, they are particularly good for the accumulation of gas bubbles that float vertically up from the mantle. The larger the space of the gas chamber formed by the fault zone, the greater the strength of the fault zone, the longer the time of collecting the underground gas in the fault zone, the greater the elastic potential energy of the gas gathered, and the stronger the earthquake produced. So each fault zone has decades, hundreds, or thousands of years of calm before a strong earthquake.

14) Casualties in meizoseismal areas are generally caused by mechanical kinetic energy such as building collapse and landslides. Some people feel uncomfortable due to breathing gases and dust during the earthquake, and no one seems to be harmed by the gases

Explanation: Because the gases released by the earthquake are the original gases that makes up the air (air that is not absorbed and converted by animals and plants), the main components are nitrogen and carbon dioxide, which are non-toxic and harmless.

15) The distribution of large seismic zones, large natural gas fields and large fault zones on the earth is consistent 
Explanation: Because the large fault zone is easy to gather the bubbles formed by the high temperature and high pressure charged gases separated by the underground magma (because the bubbles will float up under the magmatic buoyancy, and they are easy to enter the large fault zone during the process of floating), and the fault zone is easy to break, so the large fault zones are large seismic zones. And because large amounts of high temperature and high pressure charged gases often accumulate underground in large seismic zones, the gases trapped underground are released slowly for a long time before an earthquake. The release of high temperature and high pressure gases will increase the temperature of the soil and air in the seismic zone, which is good for the growth of plants. Moreover, since the gases separated by the underground magma are mainly ionized nitrogen and ionized carbon dioxide, which are the nutrients needed by plants, and ionized gas is easy to be absorbed by plants, the slow release of these gases will lead to abnormal flourishing of plants. Because earthquakes often occur in the seismic zones, the plants that grow in the seismic zones are often buried underground to form coal fields and natural gas fields. Therefore, the distribution of large seismic zones, large natural gas fields and large fracture zones on the earth is consistent

16) A huge earthquake may cause short-term increase or change in atmospheric pressure

Explanation: Earthquakes are caused by the sudden release (explosion) of high-temperature and high pressure gases formed by the accumulation of charged gas molecules separated by underground magma. A huge earthquake can cause a sudden release of large quantities of high pressure gas from the ground into the atmosphere, resulting in short-term increases or fluctuations in atmospheric pressure.

17) There are a large number of active erupting volcanoes near many fault seismic zones

Explanation: Because fractures in fault zones tend to form mantle passageways to the ground surface, and fault zones are also conducive to collecting and storing gases produced by underground magma, there are a large number of active erupting volcanoes near many fault seismic zones.

\section{Discussions}

\subsection{About Earthquake Prediction}

Because there is a high temperature and high pressure charged gas accumulation process underground in the earthquake area. The accumulation of these high-temperature and high-pressure charged gases will inevitably cause the underground pressure to rise and produce gas leakage. The rise of the underground pressure will cause the deformation (rise) of the formation, which will lead to the decrease of the groundwater level. The deformation of the formation can also lead to abnormal noise. The leakage of underground high temperature and high pressure charged gases will inevitably lead to the change of underground and 
ground temperature, humidity, electromagnetic field, air composition and air ion concentration. So it's possible to predict earthquakes by monitoring changes in those parameters.

Because earthquakes that are harmful to human beings are mainly shallow-source earthquakes whose epicenters are located in or near cities, and because shallow-source earthquakes occur in geological fault zones, we can drill some detection wells (because the ground surface air is too influenced by atmospheric changes, some wells should be used to detect variations in various parameters of the air in the well) in the fault zones in or near cities, and install relevant instruments in the wells to monitor the changes in the composition, temperature, humidity, air pressure, ion concentration, sound waves and electromagnetic field of the air in the wells over the years, and centralize the data into data analysis centers and use computers to analyze the data and predict earthquakes. The parameters to be monitored are as follows:

1) Monitor changes in air composition in the detection wells, in particular whether the concentration of nitrogen and carbon dioxide increases. The high temperature and high pressure charged gases gathered underground before the earthquake is mainly nitrogen and carbon dioxide (this can be verified by detecting the composition of the gases released by the volcanic eruptions)

2) Monitor the changes of air temperature and humidity in the detection wells, because the seismic gas that accumulates underground is hot and dry gas, the release of this gas will change the temperature and humidity of the air in the wells.

3) Monitor the change of the concentration of charged ions in the air in the detection wells. Because the seismic gas accumulated underground is high temperature and high pressure charged gases, the leakage of these gases will change the concentration of charged ions in the air in the wells.

4) Monitor sound waves from underground in the detection wells to see if any anomalies occur. Because the underground high temperature and high pressure charged gas gathering will inevitably make the underground rock bed deformation or fracture, resulting in sound waves.

5) Monitor the change of electromagnetic field in the detection wells. Because underground high temperature and high pressure charged gas accumulation and leakage will produce electromagnetic fields.

6) Monitor the change of air pressure in the detection wells. Because the leakage of underground high temperature and high pressure charged gas will change the pressure of the air in the sealed wells.

7) Monitor air flow in uncovered detection wells. Because the leakage of high temperature and high pressure charged gas underground will produce underground wind.

8) Monitor the deformation and tilt of the detection wells. Because the underground high temperature and high pressure charged gas accumulation will lead to formation rise and deformation, resulting in deformation or tilt of the detec- 
tion wells.

9) Monitoring the changes in groundwater level in detection wells. Because the underground high temperature and high pressure charged gas accumulation will lead to formation rise and deformation, resulting in the decline of the well water level.

10) Monitor whether the ground as a whole is rising (monitored by satellite and ground equipments). Because the accumulation of underground high temperature and high pressure charged gas will lead to the rise of the formation.

\subsection{The Elimination of Earthquakes and the Utilization of Seismic Energy}

The focus of the earthquake elimination is to eliminate the shallow earthquakes with a focal depth of less than $30 \mathrm{~km}$ in cities especially in large and medium-sized cities. Since most earthquakes occur in the fault zones, it can be considered to drill some deep Wells (such as $10-30 \mathrm{~km}$ deep) in the fault zones to release underground gas all the year round. Because fractures in the fault zone are covered by strata and connected to the mantle below, high pressure bubbles from the mantle can enter and accumulate in these fractures by the magmatic buoyancy. Since the underground gas that accumulates in the fault zone cannot be released into the atmosphere in time, it will accumulate more and more and the pressure will be higher and higher. When the pressure exceeds the limit, the accumulated high pressure gas will explode (the accumulated high pressure gas will open up the formation and release into the atmosphere). This is the process of shallow earthquakes. So deep Wells connected to fractures in the fault zone to release underground gas all year round can prevent shallow earthquakes from forming.

When technology is highly advanced in the future, the controlled release of this underground high pressure gas can also be used to generate electricity.

\subsection{The Conjecture of the Cause of the Ice-Age}

The temperature of the earth's surface (including the atmosphere) is affected by the radiation power of the sun, the radiation power of the sun received by the earth, and the rate at which geothermal energy (carried by magma and gases separated from it) escapes from the earth's crust.

Because the solar system moves periodically around the Milky Way, changes in the speed of the solar system's motion in the Milky Way's etheric system affect the solar radiation power, the radius of the Sun and the Earth, the distance between the Sun and the Earth, and the rate at which the Earth's internal thermal materials (magma and gases isolated from it) spill from the Earth's crust. So the surface temperature of the earth changes periodically.

1) The increase in the solar system's speed of motion in the Milky Way's etheric system will lead to a decrease in solar radiation power: According to formula (5.17) [3], the increase of the sun's motion speed in the ether of the ga- 
laxy will slow down time on the sun, that is, the speed of energy (ether) flowing from the sun to space will decrease, so the radiation power of the sun will decrease.

2) The increase in the solar system's speed of motion in the Milky Way's etheric system will lead to a reduction in the radius of the Sun and Earth: According to formula (5.31) [3], the increase in the speed of the solar system in the galactic ether will lead to a reduction in the radius of the atoms and ions that make up the sun and earth, thus resulting in a reduction in the radius of the sun and earth. A reduction in the radius of the sun and earth will result in a decrease in the power of solar radiation received by the earth.

3) The increase in the solar system's speed of motion in the Milky Way's etheric system will lead to a decrease in the distance between the Sun and Earth: It is not difficult to prove that an increase in the speed of the solar system in the galactic ether would also lead to a decrease in the distance between the sun and the earth. The decreasing distance between the sun and the earth will lead to the increase of solar radiation power received by the earth.

4) The accelerated motion of the solar system in the galactic ether will slow the rate at which hot material (magma and gas separated from the magma) in the earth's interior escape from the crust: According to formula (5.31) [3], when the solar system moves faster in the Milky Way, the speed at which the atoms that make up the earth expand with the expansion of the universe will decrease. The decrease in the rate of atomic expansion of underground magma will lead to the decrease in the rate of magmatic gas production, which will lead to the decrease in the rate of magma and high temperature gas flowing out of the earth's crust.

Since three of the above four factors, 1), 2) and 4), cause the Earth's temperature to drop, we have every reason to assume that the Earth's Ice-Age is caused by the acceleration of the motion of the solar system relative to the Milky Way at certain intervals. The greater the speed of the solar system relative to the Milky Way, the more the earth's surface temperature drops.

\subsection{The Conjecture of the Contraction and Orogenesis of the Earth Lithosphere during the Ice-Age}

Before the rupture of the earth's lithosphere, when the solar system moves to the regions of the Milky Way that make the solar system move faster, that is, those that put Earth into the Ice-Age, by the formula (5.31) [3], if the Earth's magma atoms begin to contract, it will cause the magma to stop producing gas, so the magma and the gas layer below the lithosphere will contract. In addition, the earth's surface temperature will decrease during the Ice-Age. The contraction of magma and gas beneath the lithosphere, coupled with the lowering of the earth's surface temperature, causes the lithosphere to contract. The contraction of the lithosphere causes the earth's surface to wrinkle. This may be another possible cause of orogeny. So it is possible that the orogeny was caused by the earth's 
contraction and expansion. During the Ice-Age the earth contracted and the lithosphere contracted and wrinkled to build mountains. After the Ice-Age, the earth expanded and the lithosphere continued to build mountains under local uplift caused by underground high-pressure gas and expanding magmatism.

\section{Conclusions}

1) Cosmic expansion is the dynamic force source of all planetary geological tectonic movements;

2) As the universe expands, the underground magma atoms are expanding and releasing gases. The expanding magma and high-pressure gases gathered under the lithosphere are pushing the earth to expand, changing the lithosphere shape and leading to the continuous generation of volcanic eruptions and earthquakes.

3) Seafloor spreading and continental drift are caused by the expansion of magma inside the earth, which pushes the earth's expansion so that the plates move away from each other, the gaps between the plates keep widening and new oceanic crust is constantly formed in the gaps. It is the expanding forces of magma, not the mantle convection, that cause the seafloor to spread. The so-called mantle plume and plate subduction phenomenon do not exist;

4) Since the earth is expanding and the plates are moving away from each other, the phenomena of plate collision and extrusion do not exist. Therefore, the theory that earthquakes are caused by the release of the elastic potential energy accumulated by plate extrusion and collision is not true.

5) The earthquake is caused by the explosion of high temperature and high pressure gas formed by the accumulation of charged gas molecules separated by underground magma;

6) The Earth's Ice-Age may have been caused by the acceleration of the speed of movement of the solar system relative to the Milky Way as it moves into certain regions of the Milky Way. The greater the speed of the solar system relative to the Milky Way, the greater the drop in Earth surface temperature.

\section{Conflicts of Interest}

The author declares no conflicts of interest regarding the publication of this paper.

\section{References}

[1] Ma, Z.J., Du, P.S and Hong, H.J. (2003) structure and Dynamics of the Earth, In: Chapter 1, Section 1.6 Hypothesizes on the Dynamic Force sources for the Tectonic Movement of the Earth, 1st ed. Guangdong Science and Technology Press, Guangzhou.

[2] Wu, Q.J. (2001) Recent Developments in World Seismology, No. 8.

[3] Wang, J.A. (2019) Journal of Modern Physics, 10, 1615-1644. https://doi.org/10.4236/jmp.2019.1014107

[4] Houlton, B.Z., Morford, S.L. and Dahlgren, R.A. (2018) Science, 360, 58-62. https://doi.org/10.1126/science.aan4399 
[5] Chen, Z.G. (1992) Journal of Hebei University of Geosciences, No. 6, 586-594.

[6] Wang, S.C. Sina Blog, http://blog.sina.com.cn/s/articlelist 139990610300 1.html

[7] Liang, G.H. (2016) Encyclopedia Knowledge, No. 14, 6-13.

[8] Yue, Z.Q. (2013) The Causes That Each Airs His Own Views for Strong Seismicity and the Prediction, Science Blog. http://blog.sciencenet.cn/home.php? $\bmod =$ space\&uid $=240687 \&$ do=blog\&id $=682428$

[9] Shu, L.F., Tian, X.R. and Li, H. (1998) World Forestry Research, No. 6, 42-48. 